\title{
DE RESTAURATIE VAN TWEE JAPANSE PORSELEINEN DEPOTSTUKKEN
}

In het depot van het Rijksmuseum stonden Japanse stukken die vanwege hun slechte conditie niet op zaal getoond konden worden. Tijdens onze opleiding Conservering en Restauratie van Cultureel Erfgoed aan de Universiteit van Amsterdam (UvA) restaureerden wij een grote kom van Imari-porselein (afb. I), die door eerdere restauraties was ontsierd. Ook herstelden we de ringenrand van een porseleinen fruitschaal op een hoge drievoet, één uit een set van twee identieke schalen (afb. 5).

\section{Restauratie van een Imari kom}

De porseleinen kom was ten gevolge van voorafgaande restauraties in slechte conditie. De kom is gemaakt in Arita. Deze stad groeide uit tot het centrum van de Japanse porseleinproductie nadat er in het begin

U van de $\mathrm{I} 7^{\mathrm{e}}$ eeuw koalin-klei werd ontdekt, een zeer zuivere klei die onontbeerlijk is voor de productie van echt porselein. Na I7oo werd er porselein in Imari stijl gemaakt, dat wordt gekenmerkt door een decoratie in onderglazuur blauw decoraties in rood en goud en op het glazuur. De Rijksmuseum kom is een goed voorbeeld van de vroeg $18^{\mathrm{e}}$-eeuwse Imari stijl, met een leeuw en bloemen geschilderd in het blauw en een vlinder in het rood en goud.

In 1985 werd de kom aangekocht voor de collectie van het Rijksmuseum. Toen al moet de kom gebroken zijn geweest, want in het porselein zijn de gaten te zien waar ooit de krammen zaten die de scherven bij elkaar hielden (afb. 2). Het restaureren met behulp van krammen is gedurende een lange periode een gebruikelijke techniek geweest voor het restaureren van keramische objecten. ${ }^{I}$ Hierbij werden er voorzichtig gaten geboord aan weerszijden van de breuk waarna een metalen kram over de breuk werd gespannen. De gaten werden ofwel volledig doorgeboord ofwel tot halverwege de scherf (afb. 3). Bij het eerste type bindt de kram als een lus de keramiek bij elkaar en is ze, noodgedwongen, aan beide zijden zichtbaar. Bij het tweede type klemt de kram de scherven op elkaar en is ze slechts aan één kant te zien. Hierdoor wordt de decoratie aan een van de zijden in iedere geval veel minder verstoord. De gaten in deze kom wijzen erop dat beide soorten krammen gebruikt zijn.

Het boren in de breekbare keramiek is uiteraard niet zonder gevaar en werd vaak uitgevoerd door specialisten. Tegenwoordig worden de krammen vaak gezien als een teken van de waardering die eerdere eigenaren voor het object hadden. Bij nieuwe restauratiebehandelingen wordt daarom vaak geprobeerd de krammen te behouden. Maar helaas zijn het vaak de krammen die nieuwe schade aan het object kunnen

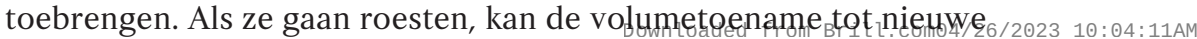


Afb. 1

Kom, Imari-decor in onderglazuur blauw, een leeuw met een vlinder tussen bloemtakken in kleuren en goud, diam. $40 \mathrm{~cm}$., Arita, Japan, 1700-1725, Rijksmuseum Amsterdam, inv. nr. AK-RBK-1985-52. Beeldmateriaal: Rijksmuseum, Amsterdam
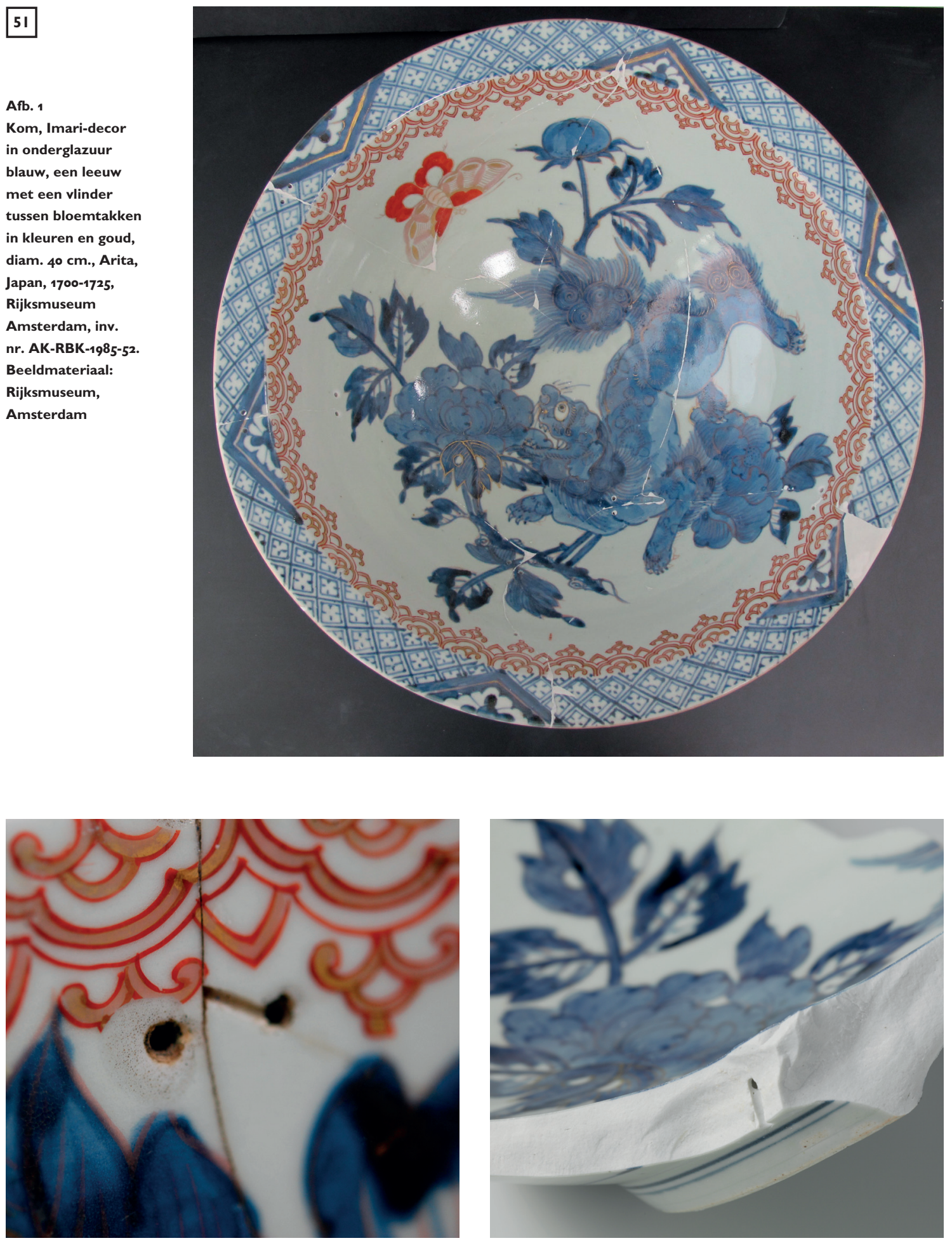

Afb. 2

Detail van kramgaten aan weerszijde van de breuklijn. Foto: Michiel Overhoff
Afb. 3

Scherf half doorgeboord.

Beeldmateriaal:

Rijksmuseum, Amsterdam.

Foto: Michiel Overhoff Downloaded from Brill.com04/26/2023 10:04:11AM 
barsten leiden. Ook kan het roestende metaal ontsierende vlekken veroorzaken. Beide omstandigheden leken zich bij deze kom te hebben voorgedaan. Er waren breuken aanwezig die nooit met een kram gerestaureerd waren, en langs de breuken waar wel ooit krammen zaten, vertoonde de scherf een roodbruine verkleuring ( $\mathrm{afb}$. 4). Bij een eerdere restauratie zijn de krammen waarschijnlijk verwijderd en zijn de breuken verlijmd. Ook was een ontbrekende scherf in de rand aangevuld. Door de jaren heen was deze aanvulling echter verkleurd waardoor ook deze aan vervanging toe was.
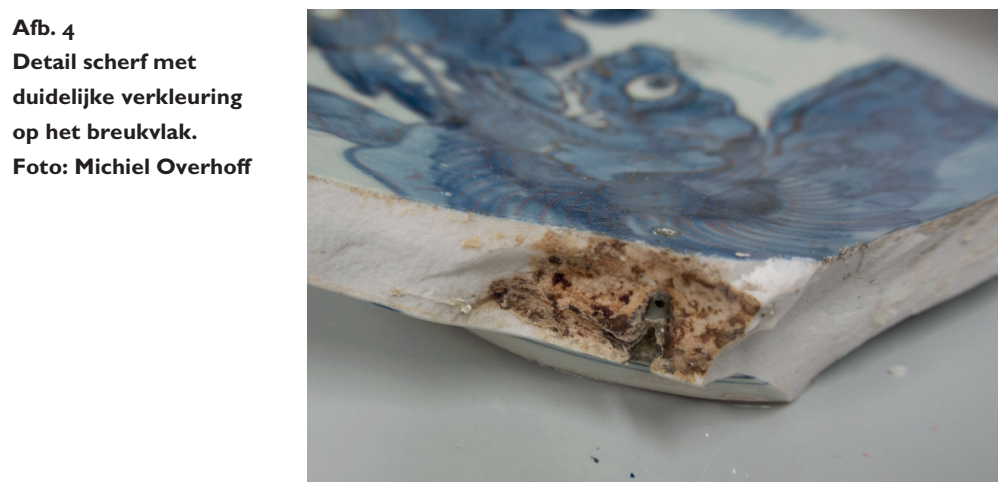

Om de verkleuringen effectief te kunnen behandelen moest de oude verlijming losgemaakt worden. Omdat het een oplosmiddellijm betrof kon dit gedaan worden door de lijm aan een geschikt oplosmiddel bloot te stellen. Hiertoe werd de kom ingepakt in met aceton doordrenkte watten en vervolgens in folie gewikkeld om de droogtijd te verlengen. Door de scherfdikte, die op sommige plekken meer dan twee centimeter bedroeg, duurde dit proces enkele weken, waarbij de kompressen regelmatig vervangen werden om uitdroging van de watten te voorkomen.

Toen de scherven eenmaal losgekomen waren, konden we de verkleuring aanpakken. Het metaal van de krammen had vlekken veroorzaakt. Dit soort vlekken hecht zich stevig aan het oppervlak van de scherf en is vaak niet (of uiterst lastig) met water te verwijderen. We hebben een gel samengesteld met twee verschillende complexvormers daarin verwerkt. ${ }^{2}$ Deze complexvormers gaan een chemische verbinding aan met de metaalionen. Bij het verwijderen van de gel worden ook de verkleurende metaalionen verwijderd. Door het herhaaldelijk toepassen van deze behandeling zijn de verkleuringen uiteindelijk met succes behandeld.

Het laatste deel van de behandeling van de kom bestond uit het opnieuw verlijmen van de scherven. Hiervoor is gebruik gemaakt van Hextal Nyl-I, een epoxy met goede verouderingseigenschappen. Ook is de ontbrekende scherf opnieuw aangevuld met gips, met uitzondering van de laatste laag die met een getinte aanvulling op basis van epoxy is gemaakt. Door de decoratie niet in de aanvulling door te zetten blijft duidelijk zichtbaar welke delen niet origineel zijn. Ook de gaatjes van de krammen zijn uiteraard - zichtbaar gelaten als sporen van de lange restauratiegeschiedenis van de kom. 


\section{De ringenrand van een fruitschaal}

Afb. 5

Schaal op een hoge drievoet met een opengewerkte rand in de vorm van elkaar overlappende cirkels, beschilderd in rode, groene en blauwe emails en goud met bloeiende planten bij een rots; ranken op de voet, porselein met emailkleuren,

h. $11 \mathrm{~cm}$. $\times$ diam. 23,5 cm., Japan, 17001725, Rijksmuseum Amsterdam, inv. nr. AK -NM-6377-B.

Beeldmateriaal:

Rijksmuseum,

Amsterdam
Het paar fruitschalen werd rond I700-I725 vervaardigd in Japan. De stijl van beschilderen doet denken aan Kakiemon, maar is het niet helemaal. Het $\mathrm{I} 7^{\mathrm{e}}$-eeuwse Kakiemon kenmerkt zich door een precieze, spitse versiering van een asymmetrisch ontwerp dat veel ruimte overlaat voor het melkwitte, verfijnde porselein. Hier zijn de kleuren blauw en groen donkerder, ook is het email onregelmatiger aangebracht, en de beschildering is in het algemeen wat onzorgvuldiger dan bij Kakiemon het geval zou zijn. De versiering vult bovendien bijna het hele vlak van de schalen. Het zijn late uitlopers van de Kakiemon stijl, die na I7oo van karakter veranderde. De situatie rond I70o was sterk in ontwikkeling, omdat de Chinese porseleinproductie na de roerige overgang van de Ming- naar de Qing-dynastie (I644) vanaf ongeveer I685 weer op gang was gekomen. Nieuwe Chinese ontwerpen kwamen op de markt en deze schalen laten de invloed daarvan zien in de donkere kleuren blauw en groen en de motieven van vlinders. Ze werden in I885 door het Rijksmuseum verworven. In dat jaar nam Het Rijksmuseum een groot deel van de collectie van het Koninklijk Kabinet van Zeldzaamheden over, waaronder veel stukken uit de verzameling van de Haagse jurist, en amateurgeleerde, Jean Theodore Royer (I737-1807). Royer bezat een

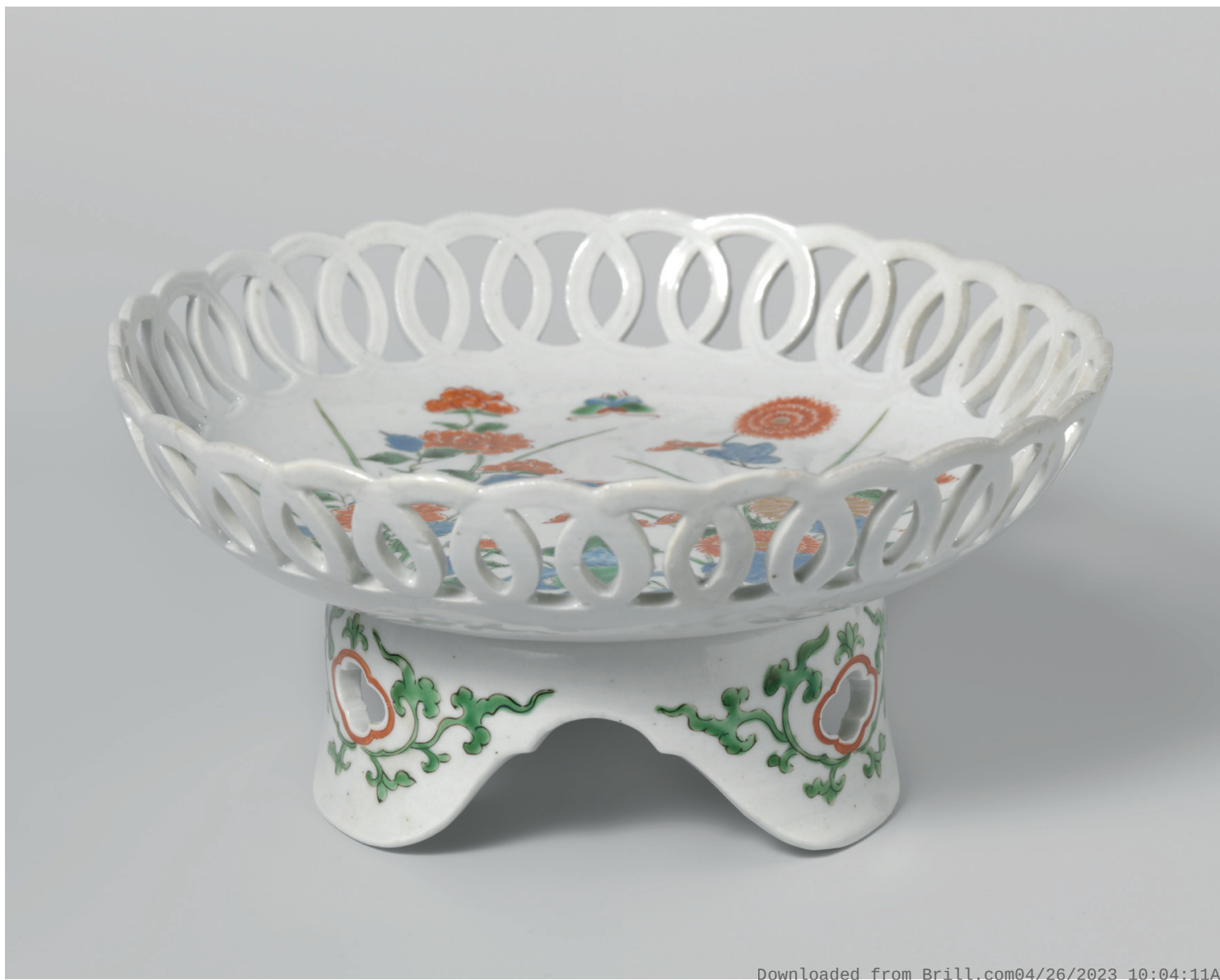


Afb. 6

Fruitschaal voor restauratie. Foto: Anniek Manshanden

Afb. 7 (linksonder) Gipsen kernen naast de lacunes. Foto: Anniek Manshanden

Afb. 8 (rechtsonder) Verlijming van de gipsen kern. Foto: Anniek Manshanden

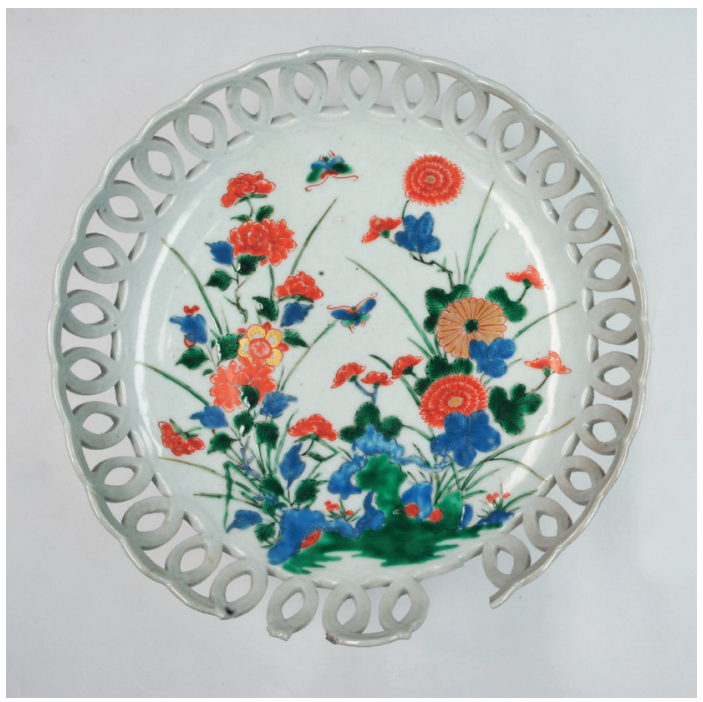

omvangrijke collectie van Aziatische voorwerpen. Hij erfde de twee fruitschalen van zijn tante Susanna Louisa Huygens (I7I4-I785), een directe nazaat van Constantijn Huygens (I596-I687). Zowel de boedelbeschrijving van Susanna Louisa Huygens als de beschrijving van Royers porselein bevatten een omschrijving van twee 'schalen met opengewerkte rand'. ${ }^{3}$

Bij een van de schalen misten enkele stukken in de ringenrand (afb. 6). Voor het aanvullen werd, zoals vaker voorkomt bij een restauratie van porselein, gebruik gemaakt van een epoxylijm: Fynebond of Hxtal NYL-I. Een epoxy heeft een vergelijkbare hardheid als die van porselein. Tevens kan de dikte worden aangepast en kan kleur worden toegevoegd. De translucentie van het porselein kan in een epoxy goed worden nagebootst. Vaak wordt bij het aanvullen gebruik gemaakt van een mal. Maar omdat de ringenrand van de Rijksmuseum schalen waarschijnlijk met de hand zijn gemaakt en daardoor niet overal gelijk zijn, bleek het niet mogelijk een mal van een compleet deel van de rand te maken en die op de missende delen te leggen. Daarom werd gekozen voor een zogenoemde
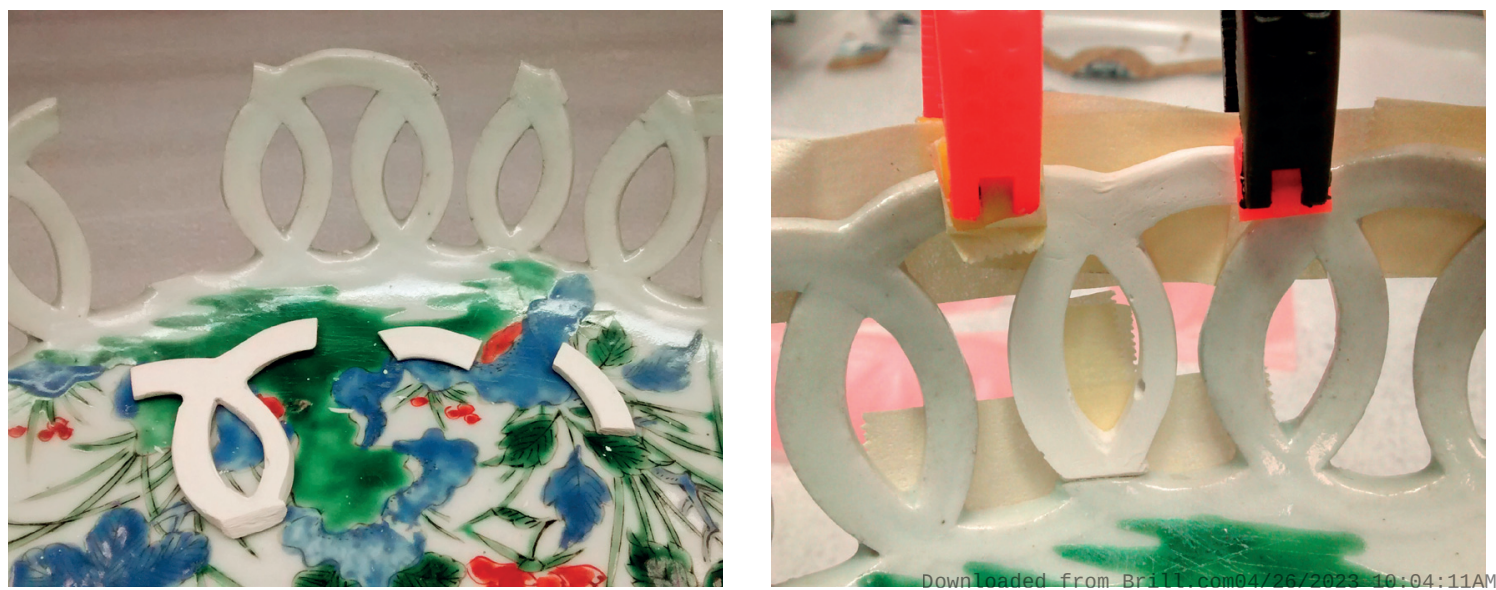
'sandwichvulling'. Bij een sandwichvulling wordt een kern van gips gemaakt waar de epoxy als een soort glazuur op wordt aangebracht (afb. 7). Omdat het porselein van de fruitschaal nagenoeg niet doorzichtig is, bleek het goed mogelijk om deze techniek toe te passen. Om de gipsen kernen te maken is gebruik gemaakt van een tweezijdige mal van een compleet deel van de ringenrand. De in gips gegoten delen zijn vervolgens op maat geschuurd en verlijmd met het object met Paraloid B72, een lijm op acrylbasis die, als dat nodig is, gemakkelijk verwijderd kan worden (afb. 8). Nadat de gipsen kernen waren beschermd met dezelfde lijm is de gekleurde epoxy in twee lagen aangebracht. Als laatste onderdeel van de behandeling zijn de aanvullingen bijgeschuurd en gepolijst om de overgangen zo onzichtbaar mogelijk te maken.

\section{Een mooi resultaat}

Beide voorwerpen hebben door de restauratie hun verloren gegane glorie teruggekregen en kunnen weer tentoongesteld worden. Wellicht kunt $\mathrm{u}$ ze in de toekomst bewonderen in het Aziatisch paviljoen van het Rijksmuseum.

- Anniek M. Manshanden studeerde Conservering en Restauratie aan de UvA. Tijdens haar opleiding liep zij stage bij het British Museum te Londen, Musée National de Céramique in Parijs, Rijksmuseum van Oudheden in Leiden, en bij privé ateliers. Zij heeft nu haar eigen restauratieatelier voor keramiek en glas, Restauratie Atelier Manshanden, in Leiden.

- Michiel W. Overhoff studeerde Conservering en Restauratie aan de UvA. Tijdens zijn opleiding liep hij stage bij Musée National de Céramique in Parijs en bij verschillende privé ateliers in binnen- en buitenland. Hij heeft nu een eigen restauratieatelier, Restauratieatelier Overhoff, in Amsterdam Noord.

\section{LIT E RAT UUR}

Jan van Campen, Vervolg op: de Haagse jurist Jean Theodore Royer (I737-I807) en zijn verzameling Chinese voorwerpen, Amsterdam, 2000 .

Jan van Campen, De Haagse jurist Jean Theodore Royer (I737-I807) en zijn verzameling Chinese voorwerpen, Hilversum, Verloren, 2000.

Renske Dooijes en Olivier Peter Nieuwenhuyse, 'Ancient repairs in archaeological research: a Near Eastern perspective', in: Ambers, J., Higgit, C., Harrison L., Saunders, D. (eds.), Holding it all together: Ancient and Modern Approaches to Joining, Repair and Consolidation, Archetype Books, London, 2009, pp. 8-13.

Isabelle Garachon, "“...Platelen cram ic" van porseleinkrammer tot keramiekreparateur', Vormen uit vuur 2I7 (2012/2), pp. 38-5I.

\section{NOTEN}

* Met dank aan Jan van Campen en Menno Fitski (Rijksmuseum Amsterdam), Kate van Lookeren Campagne (UvA) en Ingeborg Wessels-Laanbroek (restaurator).

I Dooijes en Nieuwenhuyse 2009: 8-I3 en Garachon 20I2: 38-5I.

2 Pentetinezuur (DTPA) en citroenzuur.

3 Van Campen 2000: 139 noot 214. 


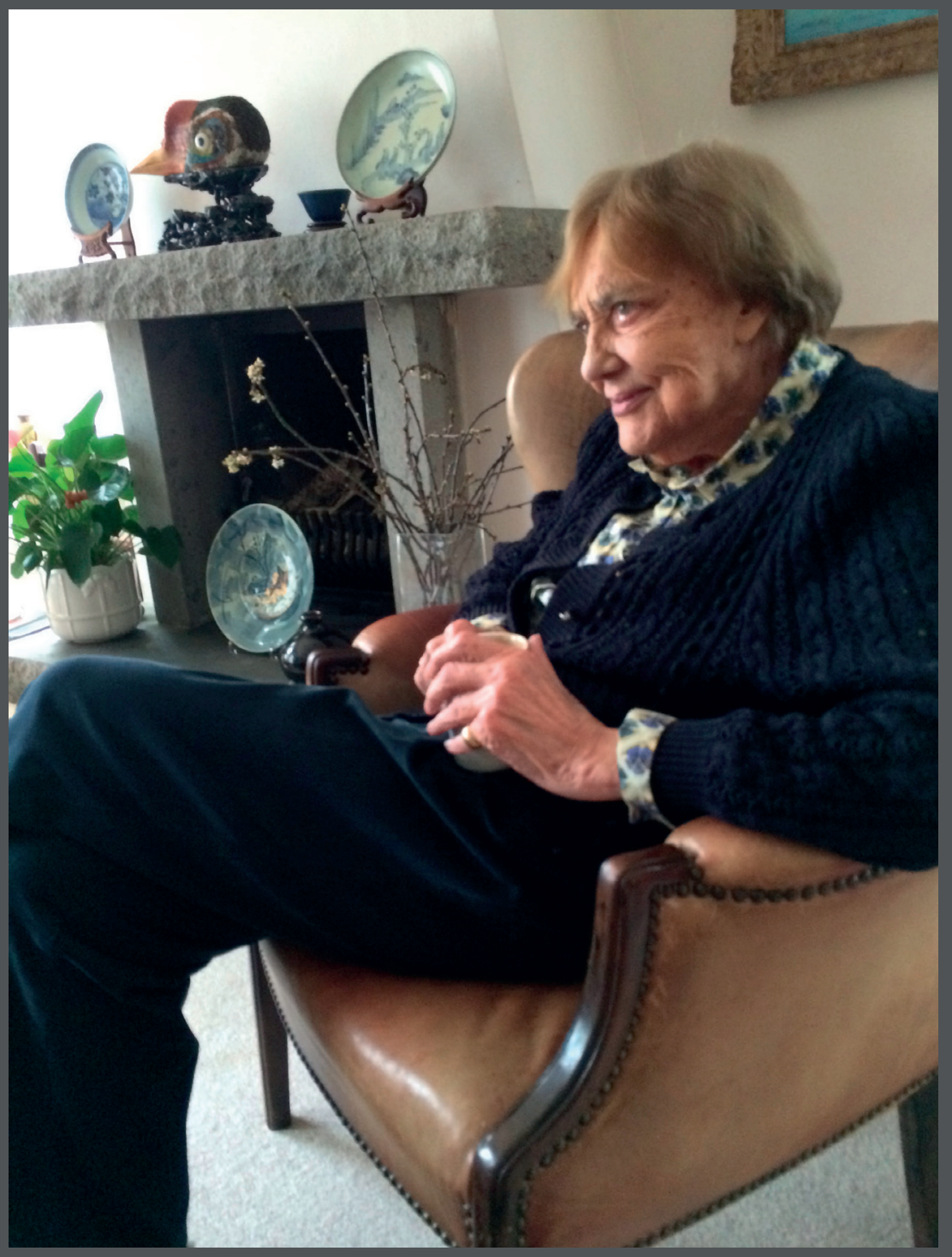

